
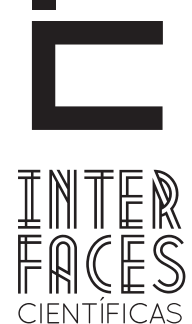

EDUCAÇÃo

\title{
HISTÓRICO DA AGRESSIVIDADE E VIOLÊNCIA NAS ESCOLAS PÚBLICAS E PARTICULARES NO BRASIL
}

Eliane de Souza Schottz
Jean Carlos Müller da Silva ${ }^{2}$

\section{RESUMO}

Este trabalho tem por objetivo trazer ao leitor uma definição da temática violência escolar, bem como compreender os mecanismos pelos quais ocorrem, identificando os autores, coautores e vítimas envolvidas, além dos ambientes em que ocorrem. A partir disso, traçar medidas de controle para essa epidemia que tem protagonizado os jornais e telejornais, com casos cada vez mais inusitados de agressão. Para tornar possível o presente estudo, adotou-se a tipologia de prática de pesquisa documental, trazendo e analisando as ideias de alguns autores estudiosos do tema. Através de um conjunto de pensamentos foi possível traçar mecanismos que permitam o controle ou até mesmo a erradicação dos casos de violência nas es- colas. Procura-se mostrar, também, o papel do professor nesse combate ao problema que vem afetando o país desde os tempos mais remotos, destaca-se ainda, a necessidade de um preparo adequado do educador para enfrentar a problemática, evitando que o mesmo se atenha apenas ao ensino de sua disciplina, estimulando uma maior interação entre professores e alunos e provar que somente assim é possível resolver ou amenizar a situação.

\section{PALAVRAS-CHAVE}

Violência Escolar. Bullying. Professores. 


\section{ABSTRACT}

This work aims to provide the reader with a definition of school violence theme, as well as understanding the mechanisms by which they occur, identifying the authors, coauthors and victims involved, besides the environments in which they occur. . From this, we draw control measures for this epidemic that has played the newspapers and newscasts, with increasingly unusual cases of aggression. To make possible this study, we adopted the practice of typology of documentary research, analyzing and bringing the ideas of some scholars the author's topic. Through a set of thoughts was possible to trace mechanisms to control, or even eradicate, cases of violence in schools. It searches also show the role of the teacher to address the problem that has been affecting the country since immemorial times, yet, stands out the need for adequate training of educators to address the problem, preventing the educator from teaching only their discipline, encouraging greater interaction between teachers and study, we adopted the practice of typology of documentary research, analyzing and bringing the ideas of some scholars the author's topic. Through a set of thoughts was possible to trace mechanisms to control, or even eradicate, cases of violence in schools. It searches also show the role of the teacher to address the problem that has been affecting the country since immemorial times, yet, stands out the need for adequate training of educators to address the problem, preventing the educator from teaching only their discipline, encouraging greater interaction between teachers and students and prove that it is the only way to resolve or ease the situation

\section{RESUMEN}

Este trabajo tiene como objetivo proporcionar al lector una definición del tema violencia escolar, así como la comprensión de los mecanismos por los cuales se producen, la identificación de los autores, coautores y víctimas involucradas además de los entornos en los que se producen. Partiendo de ese presupuesto, se trazarán medidas de control de esta epidemia protagonizada a todo momento por los periodistas, con casos cada vez más inusitados de la agresión. Para hacer posible este estudio, hemos adoptado la práctica de la tipología de la investigación documental, analizando y llevando las ideas de algunos estudiosos del tema. A través de un conjunto de pensamientos fue posible rastrear los mecanismos para controlar e incluso erradicar los casos de violencia en las escuelas. Se busca también demostrar el papel del profesor en la solución del problema que ha estado afectando al país desde tiempos remotos. Pero se destaca también, la necesidad de una adecuada formación de los educadores para abordar el problema, evitando incluso que ellos se atengan sólo a la enseñanza de su disciplina, fomentando una mayor interacción entre profesores y alumnos, y así, demostrando que esa sería una forma inteligente de afrontar y intentar solucionar o aliviar la situación.

\section{PALABRAS-CLAVE}

La Violencia Escolar. Bullying. Profesores.

\section{KEYWORDS}

School Violence. Bullying. Teachers. 


\section{INTRODUÇ̃̃̃O}

No seu amplo sentido, a violência é representada de forma particular no imaginário de cada pessoa, e assume diferentes sentidos se é vista do ponto de vista da vítima ou do agressor. Num modo geral entende-se por violência tudo aquilo que não é desejado por outrem, e que lhe é imposto pela força simbólica ou concreta (VELHO, 1996 apud MARRA, 2007). A escola é um espaço onde se concentram diferentes grupos, com objetivos comuns. Para tanto, a escola organiza-se em torno de normas de funcionamento que devem ou deveriam ser acatadas. Ao reconhecer que a escola é também um espaço de violência, abre-se margem para eliminar a ideia dessa instituição como um espaço resguardado, destinado somente à aprendizagem de conhecimentos e à formação da pessoa (MARRA, 2007).

No início da década de 1980 é que o tema violência nas escolas entra no debate público no Brasil. A partir de denúncias feitas sobre as condições precárias dos estabelecimentos escolares, traz-se à tona uma realidade até então ocultada pelo governo (SPOSITO, 2001 apud MARRA, 2007).

Sintetizar um breve histórico a cerca da violência nas escolas brasileiras é o objetivo desta pesquisa documental, o que nos faz ir além de simplesmente falar da violência em si, mas sim, procurar compreender as

\section{VIOLEิNCIA}

Segundo o dicionário Caldas Aulete (1964, p. 4321), a violência pode ser entendida da seguinte forma:

Violência é a qualidade do que atua com força ou grande impulso; força, ímpeto, impetuosidade; força que abusivamente se emprega contra o direito; opressão, tirania; constrangimento exercido sobre uma pessoa para obrigá-la a fazer ou deixar de fazer um ato qualquer; coação. razões pelas quais ocorre. Além disso, objetiva-se contextualizar as dimensões em que se manifesta e suas características. A violência na escola tem suas raízes, na violência no bairro e na família, e em variáveis estruturais como a pobreza e a privação. A partir dos pressupostos de alguns autores estudiosos do tema, apresentar-se-á uma análise reflexiva sobre a situação dessa vertente da violência e ao mesmo tempo serão apresentados métodos possíveis de resolutividade para a situação (CARDIA, 1997 apud MARRA, 2007).

Com as novas exigências na profissão, os docentes não devem estar habilitados apenas para educarem seus alunos nas disciplinas que fazem parte dos currículos, mas ir, além disso, desenvolvendo a capacidade de intervir e de evitar comportamentos agressivos. Para facilitar esse processo, existem oito elementos que devem fazer parte da formação de professores, para que se sintam aptos a lidar com os conflitos e elaborar estratégias para prevenir a violência escolar (ROYER, 2002 apud MARRA, 2007). Julga-se importante conhecer esses elementos que serão amplamente discutidos nesse trabalho. Pretende-se assim, disseminar meios para combater essa prática, tornando as escolas ambientes seguros, preservando sua finalidade de educar jovens e crianças para uma sociedade mais harmônica e pacífica.
No dicionário Aurélio da Língua Portuguesa (1986, p. 1779), violência significa "qualidade de violento; ato violento; ato de violentar; constrangimento físico ou moral; uso da força; coação". Já o Código Penal Brasileiro concebe como violência a agressão física e morte.

Ao atingir diretamente o corpo da pessoa que sofre, a violência classifica-se como direta. É classifica- 
da como indireta quando atua alterando o ambiente físico no qual a vítima se encontra. Ambas as classificações podem prejudicar terrivelmente a pessoa ou grupo que as sofrem, resultando em danos no estado físico e mental da vítima (MARRA, 2007).

Ao fazer uma análise mais humanista percebe-se que a violência vai além dessas definições. Vivencia-se a violência simbólica que se camufla sob aspectos que aparentam não ser violentos por não causar a morte física. Mas que com toda certeza contribuem para outras mortes, não só mais sofridas como também mais prolongadas, como a morte da alma, da autoestima, do ego, do ser em si. Muitas pessoas por sofrerem violência psicológica afundam-se em depressão, culminando com a morte da alma, e muitas vezes até a morte física (MARRA, 2007).

A temática violência não é uma abordagem recente na sociedade, considerando a existência de seus relatos desde os tempos mais antigos, ainda na pré-história. Porém é a partir da década de 1980 que assume grande importância na mídia, principalmente em países da Europa, Ásia e Américas.

A violência se dissipou rapidamente na sociedade, afetando diferentes segmentos e grupos sociais, entre os quais, família, escolas, instituições públicas e gerais, transportes coletivos, vias públicas, trânsito, entre outros. Sendo vitimados adultos, idosos, crianças, sejam eles alunos, professores, profissionais das mais diversas áreas. Nessa abordagem a violência é classificada de acordo com suas vítimas. Pode ser violência física, violência psicológica, violência política, violência cultural, violência verbal, violência contra a mulher, violência infantil, violência escolar, violência sexual, entre tantas outras (MARRA, 2007; CELLI, 2003).

Consiste uma tarefa difícil explicitar cada uma das violências, lista-se aqui algumas para fins de conhecimentos sobre sua existência. A abordagem se concretizará na vertente da violência escolar, que se tornou protagonista dos jornais e telejornais nos últimos anos.

\subsection{PARADIGMAS DA VIOLÊNCIA INFANTIL}

Descoberta! Essa talvez seja a característica definidora da infância. A partir do nascimento inicia-se um mundo de novas descobertas, com algum instinto a primeira delas é o seio materno, de onde se pode sugar o leite que nos supre as necessidades biológicas. Aprende-se a dar os primeiros passos e emitir as primeiras palavras. Até os doze anos de idade há um mundo de descobertas para a criança, e diversas etapas no seu desenvolvimento vão the acompanhando. Tudo isso, na maioria das vezes, a partir dos ensinamentos daqueles intitulados como pais. Evidencia-se assim, que se começa a compor a bagagem de conhecimentos, atitudes, emoções e sentimentos a partir daquilo que se vive e convive no lar (DALKA; VECINA, 2002).

Portanto, a peça fundamental nesse desenvolvimento é a família, pois durante pelo menos nove meses foi ela que se preparou interna e externamente para a chegada desse novo, ou nova, integrante que terá muito a aprender. Infelizmente, muitas das vezes esse preparo é insuficiente ou até mesmo inadequado e as consequências são terríveis. Pensando que, se para os pais existe insegurança e medo dessa nova experiência, como será para essa criança que vê nos pais o seu suporte afetivo-educacional? Esse questionamento se torna direcionador para estabelecer um adequado planejamento familiar (DALKA; VECINA, 2002).

Talvez esse questionamento permita compreender os paradigmas da violência infantil. Num primeiro estágio de desenvolvimento, os processos biopsicológicos norteiam a identidade da criança, permitindo seu desenvolvimento em conjunto ao meio facilitador: os pais. A criança a partir de seus estímulos mais intrínsecos consegue se alimentar, movimentar, chorar e emitir sons. Num segundo estágio de desenvolvimento a identidade da criança é norteada pelos processos psicossociais. É nessa fase que ela começa a herdar as riquezas ou pobrezas culturais do grupo no qual se insere, para posteriormente praticá-las na sociedade que integra (DALKA; VECINA, 2002). 
No segundo estágio de desenvolvimento da criança é que reside o verdadeiro perigo, pois é nessa fase que será definido seu caráter pessoal, baseado nas suas vivências socioculturais. Os pais têm por função ensinar aquilo que detêm como conhecimento vivenciado ou adquirido. Aos filhos cabe a incumbência de aprender, aceitando o modelo proposto e criar seu caráter em cima deles. Logo, as variações de equilíbrio do vínculo entre família e criança, assim como o desequilíbrio estrutural no caráter socioeducativo dessa família (discussões, brigas, violências física e verbal), poderá acarretar numa criança com equilíbrio prejudicado e de comportamento impetuoso (DALKA; VECINA, 2002).

Para que o processo de aprendizagem seja bem sucedido, é necessário controle e equilíbrio por parte dos pais. 0 comportamento destes deve ser harmônico, não pode haver ambiguidades. Do contrário resultará numa criança confusa e sem direcionamentos. É essencial, também, um bom preparo familiar, para que seja possível enfrentar as mais diversas situações nessa etapa de desenvolvimento. Se em algum momento não puderem resolver uma questão ou obstá- culo que se apresente nesse desenvolvimento, dificilmente poderão ajudar os filhos na aquisição de meios para isso. "[...] um bom vínculo entre pais e filhos, uma relação com confiança, espontaneidade e transparência, só é possível se cada um dos componentes dessa dupla, nesses papéis complementares, puder realizar uma aprendizagem satisfatória" (DALKA; VECINA, 2002. p. 29).

Estudos comprovam que a cada dez crianças de zero a doze anos, três sofrem, diariamente, maus tratos praticados por pais, padrastos ou familiares dentro do próprio lar, que deveria ser seu referencial de segurança e proteção. São preocupantes esses dados, pois se houver uma comunidade de mil crianças, haverá trezentos casos de maus tratos. Números assustadores, considerando que $30 \%$ dessa população é afetada em seu desenvolvimento biopsicossocial, com potencial para se tornarem os possíveis agressores do futuro. As sequelas, imediatas ou tardias, dessa terrível realidade são temerosas, incluindo as dificuldades escolares, de relacionamento social, distúrbios psicossomáticos, invalidez e morte por homicídio ou suicídio (DALKA; VECINA, 2002).

\section{A INTERFACE DA VIOLÊNCIA ESCOLAR}

Para o Ministério da Educação, a escola se subjuga como inclusiva, cidadã e solidária para todas as crianças, adolescentes e jovens brasileiros. Tem por finalidade ensinar, organizar, estimular o conhecimento e avaliar, respeitando as singularidades do desenvolvimento humano (BRASIL, 2007).

Infelizmente os noticiários jornalísticos nos reportam a uma realidade diferenciada a respeito da escola como ambiente que respeita as singularidades do desenvolvimento humano. Falar sobre violência nas escolas consiste numa tarefa árdua, exigindo criteriosidade para abordá-la. Remete-nos a alguns ques- tionamentos. Quando se fala em violência na escola, refere-se a que tipo de violência? Quem são os atores, coautores e vítimas envolvidas? E não se pode deixar de pensar, quais são as consequências que essa violência gera no ambiente escolar?

A definição do tema violência na escola é motivadora de amplas discussões e divergências entre os pesquisadores do assunto. Foram intensas e contínuas as discussões e abordagens para que se conseguisse implantar o termo violência na escola, pois era tido por muitos como uma palavra exagerada para se introduzir no ambiente escolar. 0 termo violência engloba as va- 
riações de agressões graves até as pequenas incivilidades que ocorrem nas escolas. 0 problema pode tornar-se impensável ou criminalizante e estigmatizador dos padrões comportamentais na escola, dependendo da ótica com que é visto (RUOTTI, 2006).

Ruotti (2006) considera que quatro aspectos devem ser considerados nessa temática: o surgimento de formas mais graves de violência; a idade cada vez menor dos alunos envolvidos nos casos de violência; a ação de agentes externos que ocupam o espaço da escola com agressões geradas fora dela; a repetição e o acúmulo de pequenos casos que não são necessariamente violentos. Esse último aspecto se torna preocupante por que, o que se pode considerar como pequenos casos não necessariamente violentos? Pensando que não se pode subjugar a definição de violência, esse conceito gera meios para sumariar atitudes violentas ao tratá-las como pequenos casos.

Há algum tempo a escola era vista como marco inicial para um processo de crescimento pessoal, conduzindo a um padrão de vida melhor e contribuindo para o sucesso profissional. Porém nos dias atuais, principalmente na última década, vive-se um período de crises na educação. 0 papel da escola se confunde, o perigo se torna cada vez mais iminente e o ambiente se torna desagradável, inseguro e excludente. Esse novo cenário direciona os jovens a perceberem uma desesperança e insegurança em relação ao futuro, perpetuando assim a violência na escola (RUOTTI, 2006).

\subsection{MANIFESTAÇÕES DA VIOLÊNCIA NA ESCOLA}

Entre os anos 1980 e 1990 a sobreposição do crime organizado e do tráfico de drogas, leva a um recrudescimento do sentimento de insegurança na população em geral, e paralelamente a isso a mídia destaca os casos graves de violência envolvendo a escola, com enfoque para os casos de homicídio. 0 tema vira debate público e o pânico se estabelece na sociedade entre pais e professores, que já não têm mais a certeza da escola como um local de segurança e educação. Num momento de grande demanda por segurança é que o fenômeno da violência escolar passa a ter visibilidade. Em resposta a essa nova realidade, os anos 1990 são um marco para as iniciativas públicas, em parceria com Organizações Não Governamentais (ONGs) e sociedade civil, lançarem campanhas das mais diversas, visando à redução da violência, sobretudo na escola. Grande parte desse atributo deve-se às denúncias feitas sobre as condições precárias dos estabelecimentos escolares, expondo alunos e professores ao perigo (SPOSITO, 2001 apud MARRA, 2007).

Predomina a ideia de que a escola precisa ser protegida de elementos estranhos, adota-se, assim, esquemas de proteção ao patrimônio, como o reforço do policiamento, presença de zeladores e incremento de estrutura física, como o aumento de muros e presença de grades, tornando a escola uma verdadeira prisão. Nesse contexto, fica a reflexão: o perigo está do lado de dentro ou de fora? (SPOSITO, 2001 apud MARRA, 2007).

Uma das dificuldades enfrentadas por muitos autores é justamente, definir o que pode ser considerado como violência nas dimensões da escola. Alguns estudos mostram três tipos: origem externa, quando, por exemplo, ocorre a invasão por um grupo para agredir a alguém que se encontra dentro do ambiente escolar; violência à escola, quando ocorre depredação do patrimônio ou daqueles que a compõem, como os professores; e violência da escola, quando as vítimas são os próprios alunos, vítimas de preconceitos ou paradigmas e sofrem violência por repressão, atribuição de métodos avaliativos punitivos, notas baixas, reprovações ou até mesmo agressão física (CHARLOT, 2002 apud RUOTTI, 2006).

A violência não tem um significado único, variando conforme o contexto em que se manifesta e depende dos atores envolvidos. Alguns estudos classificaram as variáveis da violência na escola em externas e internas, envolvendo atributos individuais, institucio- 
nais e ambientais. Esses fenômenos tentam de certa forma, explicar a manifestação dessa vertente da violência (ABRAMOWAY, 2002 apud RUOTTI, 2006).

Nas causas externas encontram-se: os ideais de gênero; relações raciais; estrutura familiar; influência da mídia; ambiente no qual a escola se insere. Para as causas internas tem-se: idade e nível de escolaridade; regras e disciplina; indiferença dos professores frente a cenas de violência; má qualidade de ensino e carência de recursos humanos; autoridade do corpo docente (RUOTTI, 2006).

A ocorrência de casos cada vez mais bárbaros de violência nas escolas faz com que a segurança se torne a principal preocupação entre pais, alunos e professores. Como exemplo, pode-se citar o caso, amplamente divulgado e discutido na mídia, da escola no Rio de Janeiro (caso Realengo) que foi invadida por um aluno armado com um revólver e começou a disparar tiros contra os alunos que lá se encontravam e após causar muitos ferimentos e morte, se suicidou. Pesquisas realizadas mostram que na maioria dos casos, os alunos que provocam as agressões eram sofredores de assédio moral por parte dos colegas, sofrendo piadas, gozações e discriminação (FLANNERY, 1997 apud RUOTTI, 2006).

\subsubsection{BULLYING}

Em sua definição mais concisa, o bullying é visto com um tipo de violência, física ou psicológica, caracterizada pela repetição de atos e pelo desequilíbrio de poder entre agressor e vítima (RUOTTI, 2006). Claramente falando, é algo antigo, porém, com uma abordagem recente. É comum entre os adultos, quando ocorrem certos desentendimentos entre crianças, usar a expressão "é brincadeira de criança”. É preocupante essa situação, pois algo que antes não se dava a devida importância, tem se constituído em práticas de violência nos dias de hoje, o que se pode chamar de bullying. A preocupação se remete ao fato de que as crianças de hoje serão os adultos de amanhã, e utilizar uma desculpa como essa para esconder uma forma de violência, poderá refletir perigosamente no futuro próximo e prova disso é o crescente número de casos de violência.

No ambiente escolar o bullying se apresenta em forma de xingamentos, apelidos, fofocas, empurrões, chutes, entre outras agressões que ocorrem frequentemente contra uma pessoa. Entende-se que a pessoa que prática o bullying sente-se superior cronologicamente, fisicamente ou intelectualmente à vítima. Assim, se vê, frequentemente, alunos mais velhos agredindo alunos mais novos, ou alunos fisicamente mais fortes agredindo alunos mais fracos, reduzindo as chances dedefesa da vítima por estar numa condição supostamente inferior ao agressor (OLWEUS, 1993 apud RUOTTI, 2006).

Existem dois tipos de bullying, o direto e o indireto. 0 direto é aberto à vítima e se caracteriza por ataques físicos ou verbais, já o indireto é de difícil percepção e se caracteriza por caretas ou gestos obscenos e manipulação de relacionamentos (RUOTTI, 2006).

A partir de algumas pesquisas, traçou-se o perfil das vítimas e agressores. Existem dois tipos de vítimas, as passivas e as provocativas. As passivas constituem as pessoas ansiosas, inseguras, sensíveis e quietas. Estas geralmente têm uma visão distorcida de si, com baixa autoestima. Quando agredidas reagem com choro e se afastam do agressor, sentindo-se fracassadas. Os agressores sabem que essas pessoas são alvos fáceis, porque dificilmente revidam os ataques. As vítimas provocativas apresentam ansiedade e reações agressivas, podendo desencadear uma cadeia de prática de bullying com crianças mais fracas que elas (OLWEUS, 1993 apud RUOTTI, 2006).

Em relação aos agressores, a agressividade é uma característica presente. Porém, ela se apresenta não apenas para os colegas, mas também para adultos, como pais e professores. Tendem a serem crianças im- 
pulsivas com desejo de dominar o outro, são autopositivistas. Há ainda os chamados agressores cúmplices, que a partir do início de uma briga tomam parte na mesma. Alguns consideram que aqueles que presenciam cenas de agressão e nada fazem contra tal prática, tornam-se cúmplices, também. Numa classificação por gêneros as pesquisas mostraram que os meninos estão mais envolvidos com as práticas diretas do bullying, e as meninas com as práticas indiretas do bullying (OLWEUS, 1993 apud RUOTTI, 2006).

Um fator preocupante, é que as pesquisas demonstram que os professores fazem muito pouco, ou nada, para resolver esses conflitos e conter os casos de bullying. Já os pais, principalmente daqueles que cometem as agressões, simplesmente ignoram o comportamento dos filhos na escola, tornando essa atitude um mecanismo de incentivo para tais práticas já que em momento algum são repreendidos por fazer algo errado. Há alguns sinais característicos de quem sofre o bullying, são eles: importunação repetitiva de forma vexatória; apelidos depreciativos; ridicularizações e ameaças; piadas negativas; humilhação e agressões; furtos ou danos a pertences; agressões físicas; exclusão de grupos (OLWEUS, 1993 apud RUOTTI, 2006).

As crianças vítimas de bullying passam a mudar seu comportamento e apresentam sinais que podem ser facilmente identificados pelos pais, como: roupas rasgadas ou desarrumadas ao chegar da escola; não terem amigos, nem falar sobre amigos; relutância em ir à escola; perda do apetite; dores de cabeça ou de estômago; sono agitado; perda de interesse referente a assuntos escolares; mudanças repentinas de humor, entre outros (OLWEUS, 1993 apud RUOTTI, 2006).

Faz-se necessário assim, que os pais estejam sempre atentos aos comportamentos dos seus filhos no cotidiano, que the façam indagações a cerca do dia na escola, em relação aos amigos na escola. Dessa forma será muito mais fácil identificar as práticas de bullying e agir com o propósito de inibir tal prática.
Independente do tamanho da escola e da sala de aula, seja ela no meio urbano ou rural, central ou periférica, os casos de bullying se fazem presentes. Alguns casos ocorrem no trajeto casa-escola ou escola-casa, mas majoritariamente as agressões se manifestam dentro do ambiente escolar. Algumas pesquisas citam que as agressões costumeiramente ocorrem nos intervalos das aulas, onde as crianças se concentram num espaço sem atrativos dando margem às agressões (RUOTTI, 2006).

Os casos frequentes de bullying sem nenhuma intervenção resultam em graves consequências, favorecendo comportamentos antissociais e quebra de regras que costumeiramente se estendem para a vida adulta. Pesquisas realizadas afirmam que os agressores têm chances maiores de se envolverem em casos mais graves de violência, de serem presos e ter ocorrências criminais na vida adulta. Podem continuar agindo de maneira agressiva com seu cônjuge ou filhos, criando um ciclo de violência doméstica e culminando com novas gerações de crianças agressivas. Quanto às vítimas, passam a ter um comportamento de evitação, queda no desempenho escolar, baixa autoestima, tendem ao suicídio ou homicídio do agressor, sofrem com problemas físicos e psicológicos. $\mathrm{Na}$ vida adulta tornam-se pessoas depressivas, desamparadas, envergonhadas, alcoólatras e assim como os agressores, transferem isso para o ciclo familiar (RUOTTI, 2006)

Estudos mostram que os casos de bullying são mais frequentes em escolas com alta rotatividade de professores, onde os padrões de comportamento não são estabelecidos e a disciplina foge do controle, por supervisão inadequada dos alunos (RUOTTI, 2006).

Em 2009, a Plan Brasil que é uma Organização Não Governamental de origem inglesa e defensorados direitos da infância, realizou uma pesquisa inédita em escolas brasileiras públicas e particulares com objetivo de conhecer as situações de violência entre pares e de bullying. A pesquisa ocorreu em escolas aleatoria- 
mente nas cinco regiões do país, a amostra se compôs de 5.168 alunos que responderam a um questionário. Além disso, foram selecionados quatorze grupos focais com cinquenta e cinco alunos, quatorze pais ou responsáveis e sessenta e quatro técnicos, professores ou gestores das escolas pesquisadas. 0 estudo ocorreu por meio da coleta e análise de dados tanto quantitativos como qualitativos (FANTE, 2010).

Os resultados foram impactantes, pois $70 \%$ da amostra de estudantes responderam ter presenciado cenas de violência entre colegas e 30\% afirma ter vivenciado ao menos uma situação violenta no mesmo período. 0 bullying foi praticado e sofrido por $17 \%$ dos entrevistados. Também, constatou-se que o bullying está mais presente nas regiões Sudeste e Centro-Oeste do país. A incidência maior recai sobre adolescentes na faixa etária entre 11 e 15 anos, principalmente entre os alunos da sexta série do ensino fundamental (FANTE, 2010).

Quando indagados pelos motivos de tal prática, os agressores responderam que buscam popularidade junto aos colegas, para serem aceitos pelo grupo de referência e obter fama de poderosos. As vítimas indicam que sofrem bullying devido a apresentarem diferenças em relação aos demais colegas, como um traço físico acentuado; por serem portadores de necessidade especial; por usarem vestimentas diferentes ou por terem um nível socioeconômico superior aos demais. Estas se consideram pessoas tímidas e inseguras, e assim são vistas pelos agressores (FANTE, 2010).

\subsubsection{VIOLÊNCIA FÍSICA}

Desde a mais remota antiguidade vemos casos de violência contra as crianças. Essa comprovação se faz pela citação feita por Morrow em 1948: "Você me batia nas costas e em minhas orelhas, sua doutrina penetrava". Platão em suas teorias afirma que a educação vai ser o apaziguamento da alma para ajudá-la a encontrar suas verdades ideais, tratando a infância como período de periculosidade, onde a criança não é percebida como fator de progresso. $\mathrm{Na}$ antiguidade a criança era vista como degenerescente. 0 humanismo colocava a idade do homem como realização do ciclo vital contra uma selvageria perigosa da infância (MORROW, 1948 apud DALKA; VECINA, 2002. p. 49).

Em Atenas, segundo a filosofia pitagórica "apenas a criança acabava de escapar da tirania de sua família, caia entre as mãos do pedagogo, do gramático, músico, daqueles que lhe chicoteavam, por força de seu papel para the ensinar uma arte" (GIOLITO, 1986 apud DALKA; VECINA, 2002. p. 110). Era um espetáculo apreciado, ver uma criança ser chicoteada em um desses locais destinados como escola. Receber pancadas era tido como algo comum, ao ponto de que a expressão "ter a mão sob a palmatória" era sinônimo de estudar em Roma (DALKA; VECINA, 2002). Percebe-se assim que os casos de violência contra a criança perpetuam desde os tempos mais remotos, onde se julgavam normais as agressões contra crianças, já que eram vistas como ruins.

A partir do século XIX que o cenário passa a mudar, onde os hábitos pedagógicos reduzem progressivamente as práticas repressivas até o século XX. Passa-se a abolir os castigos corporais dos textos, porém na prática ainda persistem, apesar de não denotarem mais tanta brutalidade como anteriormente. Nessa época criam-se os colégios liberais, que defendiam um aprendizado mais prazeroso e menos massacrante. Abolia o autoritarismo e práticas repressoras dentro do ambiente escolar, e assim começa-se a dar liberdade para o estudante questionar seu mestre. No Brasil essa nova tendência surge na década de 30 (DALKA; VECINA, 2002).

Com essa nova postura liberal, alguns abusos passaram a surgir, entre eles pode-se citar: estudantes malcriados passam a ser encarados como criativos; perde-se a relação hierárquica entre professor e aluno; a liberdade pedagógica é confundida com incompetência; surgem as depredações, 
agressões físicas e verbais entre alunos e professores. Hoje, o uso da força contra a criança e adolescente é reprovada, e seus direitos se afirmam pelos Estatutos criados. $O$ século $X X$ traz uma nova concepção de infância e de família, mas com o advento da violência na escola nos faz reportar ao mito da criança selvagem, e quem sabe repensar usar de certas atitudes adotadas na antiguidade, como medidas mais drásticas de educação.

\subsubsection{VIOLÊNCIA SEXUAL}

A sexualidade é entendida como um "terreno híbrido entre o pessoal e o social, encruzilhada confusa onde se articula o ser e o existir individual e coletivo de cada um de nós" (NUNES, 1987 apud DALKA; VECINA, 2002, p. 114). De uma forma mais simples, pode-se dizer que as experiências afetivas pessoais e aprendizados socioculturais de convivência estão interligados.

A partir do surgimento de civilizações mais urbanas, o sexo passa a perder seu caráter mítico, e começa a ser visto como algo que culmina em prazer. 0 homem torna-se controlador da reprodução humana por meio do sexo. É provável que a partir dessa transformação de conceito tenha-se tornado mais evidente a prostituição. $\mathrm{Na}$ época da civilização cristã, ainda no século $V$, a Igreja é quem assume o controle da sociedade, voltando aos valores espirituais e morais da sexualidade, valorizando assim a paternidade, maternidade e, sobretudo a castidade. Nessa nova perspectiva o sexo é visto como pecado e valoriza-se a estrutura familiar, onde o sexo deve ser visto apenas como meio reprodutivo e não de prazer (DALKA; VECINA, 2002).

A violência sexual compreende todos os comportamentos sexuais, dentre os quais pode-se citar: o contato físico; a exploração sexual; a prostituição infantil; a pedofilia; a pornografia; exibicionismo; entre outros. Considera-se assim, abuso sexual todas as relações onde crianças e adolescentes são utilizados por adultos para obter prazer sexual. 0 mais intrigante é que na grande maioria dos casos, esses abusos sexuais ocorrem dentro da própria residência, sendo os pais ou parentes próximos os autores de tal prática (DALKA; VECINA, 2002).

As consequências, não apenas físicas, mas também psicológicas podem ser devastadoras. Talvez essa prática seja uma das causas responsáveis pelo aumento do número de casos de doenças sexualmente transmissíveis, entre elas o HIV, entre adolescentes. Além do fato de ser cada vez mais crescente o número de adolescentes grávidas, os dados do Ministério da Saúde são assustadores. Não se pode deixar de falar nas marcas psicológicas que a criança carrega, talvez pelo resto da vida, como depressão, dificuldade de relacionamento conjugal, dificuldade de aproximação com outras pessoas do sexo oposto, medo, e em alguns casos o desfecho é o suicídio (DALKA; VECINA, 2002).

É comum nos tempos atuais encontrar-se estampadas nos noticiários, seja de jornal, televisão, rádio ou internet, práticas de violência sexual nas escolas entre os alunos, e em casos mais graves, entre professores e alunos. Percebe-se que a situação está fugindo do controle socioeducacional, onde o prazer está se sobressaindo ao saber. Nos tempos mais antigos, conforme é possível ver em filmes e telenovelas de época, era exigência obrigatória e acatada o uso rigoroso do uniforme escolar e do pudor nos ambientes escolares. Hoje não é preciso procurar muito para encontrar meninas em trajes inadequados dentro do espaço escolar, e em muitos casos se insinuando para outros alunos e professores.

Assim como se tem o oposto, muitos professores enfatizando práticas sexuais em relação aos alunos. A partir das situações expostas, têm-se argumentos suficientes para se acreditar que as crianças que sofrem abuso sexual, seja em casa ou na escola, poderão se tornar futuros agressores ou abusadores. 


\subsubsection{VIOLÊNCIA ENTRE ALUNOS}

De acordo com relatos dos professores, a maior parte das agressões físicas entre alunos surge a partir de insultos verbais. Dentre os quais se destacam: os xingamentos; os apelidos; chacotas e humilhações, o que pode-se definir como bullying (RUOTTI, 2006).

Outro ponto curioso levantado pelos professores é a mudança do padrão das agressões físicas entre alunos, pois há algum tempo as agressões ocorriam entre meninos e meninos, meninas e meninas. Porém, a realidade hoje é meninos e meninas se agredindo verbalmente e fisicamente. De certa forma, conforme os professores havia certo respeito nas diferenças de gêneros, que hoje se perdeu completamente. Percebe-se assim que cada vez mais a agressão se faz presente e vai transformando seus padrões de inserção. Talvez essas práticas tenham sido um dos fatores contribuintes para a criação da Lei Maria da Penha, que visa defender as mulheres agredidas física ou verbalmente por pessoas do sexo oposto, já que as agressões contra o gênero feminino têm sido cada vez mais frequentes, conforme pode-se constatar nos noticiários (RUOTTI, 2006).

Ainda segundo o relato dos professores, há uma distinção entre os padrões das brigas entre as crianças e os adolescentes. Em relação às crianças, as brigas costumam a ocorrer dentro das salas de aula ou dentro do espaço escolar. Já entre os adolescentes, frequentemente as brigas ocorrem fora do ambiente escolar, o que pode configurar um padrão mais grave por não haver um controle por parte da escola. Quando ocorrem dentro da escola, fica mais fácil para contê-las e impor medidas educativas e/ou punitivas. Fora da escola fica mais difícil esse controle, assim como não se podem impor medidas punitivas, e as lesões físicas tendem a ser mais graves (RUOTTI, 2006).

\subsubsection{VIOLÊNCIA CONTRA PROFESSORES}

Conflitos e desentendimentos são as palavras que de modo geral definem a relação entre professores e alunos, de acordo com pesquisa realizada entre os docentes. A escola é um espaço onde se encontram os mais diferentes processos culturais, pois agrega diferentes pessoas com personalidades próprias, onde na maioria das vezes os meios culturais se confrontam dando espaço às brigas, discussões e num processo mais avançado, agressões físicas permeadas por intrigas (RUOTTI, 2006).

Conviver nos diferentes meios e acima de tudo respeitá-los, é algo que deve fazer parte do aprendizado escolar. Vale dizer que o conflito de ideias nem sempre deve ser encarado como algo negativo, pois a partir da divergência de ideias é que surge o conhecimento. Se seria muito diferentes do que se é hoje e provavelmente menos evoluídos se, por exemplo, todos pensassem de modo igual. A divergência de opiniões e ideias se faz necessária; e mais necessário ainda é saber utilizar os conflitos de forma positiva.

Além das agressões físicas sofridas pelos professores, citam-se nas pesquisas os danos causados, por alunos, em seus carros. Esses danos incluem desde simples riscos até danos maiores como vidros e espelhos quebrados, carros pichados, retrovisores arrancados, entre outros. Os professores acreditam que essas ações não se tratam apenas de simples vandalismo, mas sim de atitudes que visam represálias, intimidação e coação devido posicionamento contrário ao dos alunos. Nos depoimentos também fica claro, que os professores sentem-se como reféns de seus alunos (RUOTTI, 2006).

A insegurança sentida pelos professores reflete diretamente na qualidade de ensino dos alunos, pois ao ministrarem suas aulas com medo de represálias acabam por não passar adequadamente seus conhecimentos. Numa perspectiva de tornar as aulas e a disciplina mais fácil ou acessível para o nível dos alu- 
nos, omitem o verdadeiro conhecimento que se faz necessário nos dias atuais. Os professores tem verdadeiramente medo de aplicar uma nota baixa ao aluno que vai mal numa prova, por exemplo, e se obriga a aprovar um aluno que não tem a menor condição de ser aprovado. 0 mais revoltante é que nos tempos atuais, os pais muitas vezes, ainda se posicionam contra o professor que reprova o aluno que não tem condições de ser aprovado. 0 resultado desse impasse é o que vemos estampado nas manchetes dos jornais diariamente: professores agredidos por alunos e muitas vezes por pais de alunos (RUOTTI, 2006).

\section{MECANISMOS DE CONTROLE DA VIOLÊNCIA ESCOLAR}

A organização social da escola reforça e afirma a superioridade dos professores, diretores e demais profissionais de seu mundo e, naturalmente os professores são os líderes por excelência. Porém, os alunos estão em maior número e dessa forma as sanções logo se esgotam. Usar da demonstração de forças e poder tende a provocar um desgaste progressivo evoluindo para reações de agressividade.

Com as novas exigências na profissão, os docentes não devem estar habilitados apenas para educarem seus alunos nas disciplinas que fazem parte dos currículos, mas ir além disso, desenvolvendo a capacidade de intervir e de evitar comportamentos agressivos. Para facilitar esse processo, existem oito elementos que devem fazer parte da formação de professores, para que se sintam aptos a lidar com os conflitos e elaborar estratégias para prevenir a violência escolar (ROYER, 2002 apud MARRA, 2007).

0 primeiro elemento é a necessidade de mostrar aos professores que a violência não é natural e necessita ser pensada no contexto em que se insere, lem-
Segundo dados do Ministério da Educação em 2011, 4,2 mil professores de português e matemática da $5^{a}$ e $9^{a}$ séries da rede pública e privada de ensino fundamental, foram agredidos fisicamente por alunos dentro das salas de aula, nos corredores ou nas saídas da escola. Esses dados foram obtidos por meio de um questionário com a participação de 225 mil professores, ou seja, $1,9 \%$ do total de docentes foram agredidos no respectivo ano. Ao se considerar os valores em percentual talvez não represente algo tão grave, mas se se consideram os números, conclui-se que é simplesmente assustador, pois são mais de 4 mil professores vitimados num universo de 225 mil docentes.

brando que muitas vezes a violência está enraizada na pobreza, na miséria, na privação e na violência intrafamiliar. É necessário que o professor saiba enfrentar essas situações, buscando primeiramente compreender o que leva a criança a agir violentamente, e assim agir exatamente na raiz do problema. Pois se a criança presencia cenas de violência em seu próprio lar, ela apenas reproduz na escola o que aprende em casa, e não resolverá o professor simplesmente repreendê-la. Necessita agir no núcleo familiar, e nessa situação será necessário ajuda de outros profissionais, como o Conselho Tutelar, por exemplo, ou o Serviço de Assistência Social do Município, ou ainda um serviço de Psicologia, quando disponível (ROYER, 2002 apud MARRA, 2007).

O segundo elemento é acreditar que a escola realmente pode contribuir para evitar a violência. No julgamento popular a escola é considerada como a segunda casa do aluno, então significa dizer que além do papel educativo, a escola tem como função educar o aluno para a vida em sociedade. Cabe ao professor, mostrar aos alunos o papel negativo que a violência tem para a 
sociedade, bem como as consequências que esses atos violentos podem trazer tanto para as vítimas, como para os agressores. Pois se a criança agressora não tem em seu lar um adequado suporte familiar, ela com certeza não terá noção nem tão pouco dimensão dos problemas que esses atos poderão lhe acarretar, cabe ao professor, enquanto mestre, clarear aos alunos essa abordagem tendo por objetivo final reduzir ou evitar os casos de violência no ambiente escolar, e fora dele (ROYER, 2002 apud MARRA, 2007).

O terceiro elemento aborda a necessidade dos professores estarem alertas à obrigatoriedade de intervirem de forma ativa e não reativa aos problemas que ocorrem dentro da escola. É comum muitos professores presenciarem cenas de violência e em certas situações, fechar os olhos numa tentativa de não encarar a situação por medo da reação dos alunos agressores. Porém, cabe ao professor a atitude de erradicar a violência dentro do espaço escolar e, sempre que possível, fora dele. Vale aqui deixar claro também, que não resolverá simplesmente aplicar advertências ou suspensões como método punitivo. Ė necessário agir em conformidade com os outros elementos supracitados, pois do contrário, será apenas uma reação e não uma ação contra os métodos agressivos (ROYER, 2002 apud MARRA, 2007).

O quarto elemento indica a necessidade de respeitar o contexto no qual a escola se insere, e deve-se pensar uma intervenção que atenda à demanda particular de cada situação. Não é porque uma escola está inserida numa favela, por exemplo, que significa que todos os casos de violência terão a mesma raiz. É preciso tratar cada caso com individualidade e traçar as metas de acordo com a realidade de cada envolvido. É notório que a questão das drogas e seu tráfico, se fazem mais presentes nas comunidades de periferias, como as favelas, e isso requer uma atenção especial por parte dos professores para tratar do assunto. $\dot{E}$ importante envolver a família nessa luta (ROYER, 2002 apud MARRA, 2007).
O quinto elemento é tido como essencial, visa à atualização das informações dos professores sobre o tema em questão. Esse sem dúvidas é o ponto chave, pois para que os professores possam agir é necessário que estejam atualizados e atentos às novas demandas que o tema exige. Torna-se fundamental que conheçam o contexto da violência no bairro que a escola se insere, assim como no município, no estado e no país. A partir disso, devem-se buscar as alternativas adotadas, como as políticas públicas, pelos diferentes órgãos governamentais e não governamentais, como medidas de controle para a situação (ROYER, 2002 apud MARRA, 2007).

0 sexto elemento enfoca a questão da necessidade de pesquisas confiáveis a respeito do tema, para, a partir delas, estabelecer uma política de formação continuada para os professores. Essa é uma responsabilidade do governo, que deve prezar pela constante atualização de seu corpo docente. As pesquisas são importantes, pois traduzem cada realidade de forma exponencial, e a partir disso é possível traçar metas para controle das situações mais alarmantes e estabelecer os potenciais causadores da violência de forma individualizada (ROYER, 2002 apud MARRA, 2007).

O sétimo elemento é fundamental para o sucesso do objetivo final, consiste em envolver os pais dos alunos nos projetos realizados pela escola. Não surtirá efeito simplesmente abordar o problema em sala de aula, sem levar em consideração o ambiente e suporte familiar que o aluno dispõe. È importante que os pais compreendam todo o processo e seu objetivo, para que possam ser a extensão da escola no combate à violência. Muitas vezes, por inexperiência, os pais não tem noção de que seus comportamentos influenciam no comportamento de seus filhos, e que se eles promoverem brigas no ambiente intrafamiliar há uma grande possibilidade de seus filhos repercutirem a cena no ambiente escolar, pensando ser esse um comportamento normal, pois seus pais são seu referencial de educação e comportamento (ROYER, 2002 apud MARRA, 2007). 
O oitavo elemento baseando-se no anterior, aponta que é necessário também envolver a comunidade nesse processo. Talvez, esse seja o passo final para estabelecer uma situação de apaziguamento, não apenas dentro da escola, mas fora dela também. Com o envolvimento comunitário é possível repercutir todos esses meios de combate não só à violência, mas também à criminalidade. É importante adotar medidas inclusivas por meio dos serviços oferecidos pela comunidade em geral, visando aumentar a lei da procura e da oferta. Se por exemplo, uma das causas de violência e criminalidade na comunidade escolar, for motivada pela miséria tendo como raiz o desemprego familiar, talvez adotando uma parceria comunitária para estimular a oferta de emprego para essa família, possa contribuir para a redução desses índices que se tornam cada vez mais crescente de acordo com as estatísticas (ROYER, 2002 apud MARRA, 2007).

Em consonância a essas medidas de controle da violência escolar, ainda encontra-se a Campanha "Aprender sem Medo", lançada pela Plan Brasil. Esta ONG tem como princípio que assegurar o direito de crianças e adolescente é uma missão e não apenas uma escolha. Atua capacitando comunidades para fazer valer esses direitos. Está presente em mais de 60 países, no Brasil foi implantada no ano de 1997 e desde então desenvolve programas na área da saúde, da educação e direitos das crianças. Para o sucesso dessa campanha se faz necessário o envolvimento das três esferas de governo, das comunidades e indivíduos. 0 foco principal é permear o cumprimento das Leis existentes que protegem as crianças e adolescentes, como o Estatuto da Criança e do Adolescente - ECA (FANTE, 2010).

Não se pode deixar de mencionar, também, um marco importante na história da educação brasileira como medida de proteção aos professores vítimas de agressões: o Projeto de Lei do Senado Federal $n^{\circ}$ 191, de 2009 - PL 191/2009. Esse PL prevê "procedimentos de socialização e de prestação jurisdicional e prevê medidas protetivas para os casos de violência contra o professor oriunda da relação de educação" (BRASIL, 2009).

Conforme o artigo $2^{\circ}$ da referida Lei, considera-se violência contra o professor: "qualquer ação ou omissão decorrente da relação de educação que lhe cause morte, lesão corporal ou dano patrimonial, praticada direta ou indiretamente por aluno, seus pais ou responsável legal, ou terceiros face ao exercício de sua profissão" (BRASIL, 2009).

\section{CONSIDERACÕ̃ES FINAIS}

Ao contextualizar a violência percebeu-se que ela é individualizada, ou seja, cada pessoa dispõe de um conceito próprio do tema que é visto de diferentes maneiras. Simplificando pode ser definida como uso de força abusiva.

A escola passou por um processo de transformação em seu caráter educativo, a insegurança e o temor da violência se destacam em relação ao desejo pelo aprendizado. A necessidade de definir a violência é fundamental para estabelecer planos de ação, metas de controle e erradicação desta que perpetuou a insegurança na escola.

Apesar do tema não ser recente é evidente o receio com o qual é abordado, sendo amplamente discutido apenas a partir da década de 1980. Com estudos mais frequentes e ampliados foi possível classificar a violência em subtipos e estabelecer procedimentos de combate diversificados. 
Falar de violência infantil, faz definir a responsabilidade dos pais ou responsáveis enquanto educadores. É a partir das ações destes que a criança estabelece seu caráter e personalidade. As crianças fazem de seus responsáveis uma espécie de espetho, e serão o reflexo desse espelho na sua infância, adolescência e vida adulta. Portanto é fundamental a abordagem e envolvimento dos pais no combate às práticas violentas, pois os estudos comprovaram que são diversas as sequelas que essas práticas podem acarretar para as crianças no seu processo de desenvolvimento.

As pesquisas levam a acreditar que a escola perdeu seu caráter educativo e seu status de ambiente seguro, tornando-se cenário de massacres, monstruosidades, agressões e práticas ofensivas. Esses resultados servem de alerta para se resgatar o verdadeiro papel da escola enquanto centro de ensino, possibilitando a retomada do seu conceito de local seguro para aprendizado.

Merece destaque, também, o papel de controle social que as ONGs e comunidade exercem, e devem exercer, em consonância com as políticas públicas criadas para estimular e promover a segurança no ambiente escolar, objetivando a erradicação das práticas violentas em qualquer que seja o ambiente.

O bullying é citado como uma das agressões mais presentes na escola, e devido ao seu caráter repetitivo e covarde pode acarretar à vítima sérias sequelas não somente físicas, mas, sobretudo psicológicas. Essas marcas talvez nunca sejam apagadas da memória da pessoa que as sofreram. Essa prática deve ser amplamente combatida e é de suma importância a atenção dos pais em relação aos filhos para que possam reconhecer sinais que caracterizam o sofrimento de bullying.

Com o passar dos anos, o sexo transformou seu caráter reprodutivo em prazeroso. As práticas de violência sexual emergem na mídia e as vítimas na maioria dos casos são as crianças e adolescentes. Fato que contribui para o aumento do número de casos de doenças sexualmente transmissíveis e gestação entre adolescentes.

Curioso também foi a mudança percebida dos padrões na violência entre os alunos, onde perde-se o respeito que os meninos tinham em relação às meninas. Os professores perdem o respeito dos alunos e a garantia de segurança em seu ambiente de trabalho. O comprometimento da qualidade de ensino devido à insegurança gerada traz a necessidade de medidas emergenciais de controle da situação e mudança da realidade por meio da implantação de alguns elementos que visam a erradicação da violência no âmbito escolar.

A realização desta pesquisa foi bastante satisfatória a partir do momento que possibilita traçar um perfil da violência escolar, e por meio deste perfil implantar medidas de controle desta triste realidade. Acredita-se que isso seja possível a partir da criação de Campanhas de Combate à Violência em parceria entre governo, ONGs e comunidade. Um grande avanço nesse campo foi a criação do Projeto de Lei $n^{\circ}$ 191 de 2009 pelo Senado Federal, que visa defender os professores em seu âmbito de trabalho, contra as práticas violentas. É importante destacar a necessidade dos educadores estarem sempre atualizados em relação ao tema para que seja possível uma redemocratização da sociedade resultando na extinção da violência em todas as suas manifestações. 


\section{REFERÊNCIAS}

BRASIL. Ensino fundamental de nove anos: Orientação para a inclusão da criança de seis anos de idade. Brasília: Ministério da Educação, 2007.

BRASIL. Projeto de Lei do Senado no 191 de 2009. Brasília: Senado Federal, 2009. Disponível em: <http://www.senado.gov.br/atividade/materia/getPDF.asp?t=58252>. Acesso em: 15 abr. 2013.

CELLI, M. A. E..Violência nas escolas: versão resumida. Brasília: UNESCO, 2003.

DALKA, C. A. Ferrari; VECINA, Tereza C. C. 0 fim do silêncio na violência familiar: Teoria e Prática. São Paulo: Ágora, 2002.

FANTE, Cleo. Aprendendo a prevenir o bullying na escola: Campanha Aprender sem Medo. Maranhão: Plan Brasil, 2010.
MARRA, Cecília Auxiliadora dos Santos. Violência escolar: a percepção dos atores escolares e a repercussão no cotidiano da escola. São Paulo: Annablume, 2007.

O Aumento da violência escolar. O Estado de São Paulo, São Paulo, 26 fev. 2013. Opinião. Disponível em: <http://www.estadao.com.br/noticias/impresso,o-aumento-da-violencia-escolar-,1001569,0.htm>. Acesso em: 20 abr. 2013.

RUOTTI, Caren. Violência na escola: um guia para pais e professores. São Paulo: Andhep, 2006.

\author{
1 Mestrado e graduação em Ciências Biológicas pela Universidade Federal \\ do Paraná (UFPR); Docente da Rede Pública do Estado do Paraná. \\ 2 Graduado em Enfermagem pela Universidade Federal de Santa Catarina. \\ (UFSC).
}

